\title{
Aplicação de bioestimulantes e Bacillus subtilis na germinação e desenvolvimento inicial da cultura do milho
}

\author{
Antonio Carlos Buchelt ${ }^{1}$, Carlos Renato Metzler $^{2}$, José Lucas Castiglioni' ${ }^{2}$ Tiago Ferrarezi \\ Dassoller $^{2}$, Matheus Sergio Lubian ${ }^{2}$
}

\author{
${ }^{1}$ Universidade Estadual Paulista "Júlio de Mesquita Filho”, Campus de Jaboticabal, Jaboticabal, São Paulo, Brasil. E-mail: \\ antoniobuchelt@hotmail.com \\ ${ }^{2}$ Universidade do Estado de Mato Grosso, Campus de Alta Floresta, Alta Floresta, Mato Grosso, Brasil. E-mail: \\ renatometzler@hotmail.com, lucas.cgt@hotmail.com,mgmdassoller@hotmail.com,matheussergiolubian@gmail.com
}

Recebido: 17/06/2018; Aceito: 01/11/2019.

\section{RESUMO}

O presente trabalho teve como objetivo avaliar a germinação e o crescimento inicial da cultura do milho em sementes submetidas à aplicação de bioestimulantes (ProGibb $400^{\circledR}$ e Stimulate ${ }^{\circledR}$ ) e de Bacillus subtilis. O experimento foi realizado no laboratório de tecnologia e sementes da Universidade do Estado de Mato Grosso, Campus de Alta Floresta. O delineamento utilizado foi o inteiramente casualizado, com dez tratamentos com quatro repetições de 25 sementes cada. Os tratamentos utilizados foram: Testemunha, ProGibb $400^{\circledR} 1,2$ e 3 com doses respectivas de 25,50 e $75 \mathrm{mg} \mathrm{kg}^{-1}$ de sementes, Stimulate ${ }^{\circledR} 1,2$ e 3 com doses respectivas de 5,10 e $15 \mathrm{~mL}$ $\mathrm{kg}^{-1}$ de sementes e Bacillus subtilis 1, 2 e 3 com doses respectivas de 4,6 e $8 \mathrm{~mL} \mathrm{~kg}^{-1}$ de sementes. Os parâmetros avaliados foram: germinação, comprimento da parte aérea, comprimento das raízes, massa fresca da parte aérea, massa fresca das raízes e massa seca da parte aérea e das raízes. As aplicações dos bioestimulantes e do Bacillus subtilis não influenciaram na germinação, comprimento das raízes e comprimento da parte aérea, massa fresca da parte aérea e massa seca das raízes na cultura no milho. A aplicação do ProGibb $400^{\circledast}$ na cultura do milho aumenta o comprimento da parte aérea e a massa seca no início do desenvolvimento.

Palavras-chave: Zea mays, hormônio vegetal, tratamento de sementes, tecnologia.

\section{Application of bio-stimulants and Bacillus subtilis in the germination and initial development of corn culture}

\begin{abstract}
The study aimed to evaluate the germination and initial growth of the corn submitted to seed treatment with biostimulants (ProGibb 400® and Stimulate ${ }^{\circledR}$ ) and Bacillus subtilis. The experiment was carried out in the Technology and Seed Laboratory of the State University of Mato Grosso, Campus de Alta Floresta-MT. Completely randomized design, with ten treatments and four replications of 25 seeds each, were used. The treatments were Control, ProGibb $400 \circledast 1,2$ and 3, with respective doses of 25,50 and $75 \mathrm{mg} \mathrm{kg}-1$ of seeds, Stimulate ${ }^{\circledR} 1,2$ and 3, with respective doses of 5, 10 and $15 \mathrm{~mL} \mathrm{kg-1}$ of seeds, and Bacillus subtilis 1,2 and 3, with respective doses of 4, 6 and $8 \mathrm{~mL} \mathrm{kg-1}$ of seeds. Germination, shoot length, root length, and fresh and dry matter of shoots and roots were evaluated. The application of biostimulants and Bacillus subtilis did not influence the germination, root length, total length, shoot fresh matter and root dry matter of corn plants. The application of ProGibb $400 ®$ increases the shoot length and dry matter of corn plants at the beginning of growth.
\end{abstract}

Keywords: Zea mays, plant hormone, seed treatment, technology. 


\section{Introdução}

O milho (Zea mays) é um dos principais cereais cultivados no mundo, sendo que, a partir dos seus grãos, são fornecidas grandes quantidades de produtos amplamente utilizados na alimentação humana, animal e matérias-primas para a indústria, principalmente em função da quantidade e qualidade das reservas acumuladas nos grãos (Alves et al., 2015). Nos últimos anos, tecnologias vêm sendo implementadas nas culturas agrícolas, principalmente na cultura do milho, visando melhorias na qualidade de sementes e, consequentemente, no aumento da produção. O tratamento de sementes com fungicidas, inseticidas, micronutrientes, bioestimulantes e microrganismos é uma das tecnologias fundamentais nesse meio, que pode ser aplicado para proteger a cultura nos seus estágios iniciais.

Os bioestimulantes são substâncias naturais ou sintéticas, provenientes da mistura de dois ou mais biorreguladores vegetais (auxinas, giberelinas, citocininas, retardadores e inibidores, e o etileno) ou outras substâncias como aminoácidos, nutrientes e vitaminas, podendo ser aplicados inteiramente nas plantas ou no tratamento das sementes. Sua utilização visa obter maiores e melhores resultados na produção e qualidade das mesmas (Klahold et al., 2006). Esses produtos podem estimular o crescimento vegetal, proporcionando aumento da divisão celular e otimizando a capacidade de absorção de água e de nutrientes minerais, essenciais para a produtividade das culturas (Silva et al., 2008; Bertolin et al., 2008), assim como provocam alterações estruturais responsáveis pelo aumento do vigor das sementes (Dourado Neto et al., 2014).

Diversos estudos demonstram que a aplicação de bioestimulantes na cultura do milho tem apresentado ganhos significativos na produtividade e incremento do sistema radicular, como no trabalho de Santos et al. (2013), que observaram efeito positivo do uso de bioestimulador em todas as etapas de desenvolvimento, principalmente em variáveis radiculares. No entanto, alguns estudos mostram que o uso dos bioestimulantes pode não favorecer a cultura do milho, resultado este constatado por Bontempo et al. (2016), onde observaram que a aplicação de bioestimulantes não influenciou na emergência e no crescimento inicial de plantas. Portanto, a resposta da aplicação dos bioestimulantes depende de diversos fatores, entre eles a composição das substâncias húmicas presentes nos produtos usados, sendo necessários mais estudos sobre o efeito desses produtos no desenvolvimento da cultura do milho.

Além da utilização dos bioestimulantes, uma tecnologia que vem sendo muito empregada na agricultura é a utilização de rizobactérias promotoras de crescimento de plantas (RPCPs), e entre elas uma das mais importantes é o Bacillus subtilis, à qual é atribuída a síntese de fitohormônios, como ácido indolacético, ácido abscísico, giberelinas e citocininas, favorecendo o aumento do número de pelos radiculares e o crescimento do sistema radicular das plantas (Araújo e Hungria, 1999), bem como a absorção de água e nutrientes, possibilitando uma maior produção de grãos. Poucos são os trabalhos e resultados com a utilização dessas rizobactérias na cultura do milho; em um desses trabalhos, Junges et al. (2013) constataram que a aplicação desse microorganismo em sementes de milho não afetou a germinação das sementes e promoveu aumento no crescimento e desenvolvimento das plântulas.

Portanto, tornam-se essenciais estudos evidenciando efeitos dos bioestimulantes e do Bacillus subtilis na germinação e no crescimento inicial da cultura do milho. Considerando a hipótese de interação benéfica de bioestimulantes e dos produtos biológicos no desenvolvimento das plantas de milho, objetivou-se com esse trabalho avaliar o efeito de PROGIBB $400^{\circledR}$, Stimulate ${ }^{\circledR}$ e Bacillus subtilis no potencial germinativo e crescimento inicial da cultura.

\section{Material e Métodos}

O experimento foi conduzido no Laboratório de Tecnologia de Sementes e Matologia (LaSem) da Universidade do Estado de Mato Grosso (UNEMAT), Câmpus Universitário de Alta Floresta, no mês de abril de 2017.

O delineamento experimental utilizado foi inteiramente ao acaso, sendo composto por dez tratamentos e quatro repetições com 25 sementes cada. Os tratamentos utilizados foram: Testemunha (sementes não tratadas); Bacillus subtilis 1, 2 e 3 com doses respectivas de 4, 6 e $8 \mathrm{~mL} \mathrm{~kg}^{-1}$ de sementes; ProGibb $400^{\circledR}$ (Giberelina 40\%) 1,2 e 3 com doses respectivas de 25,50 e $75 \mathrm{mg} \mathrm{kg}^{-1}$ de sementes e Stimulate $^{\circledR}$ $(0,009 \%$ de cinetina, $0,005 \%$ de auxina e $0,005 \%$ de ácido giberélico) 1, 2 e 3 com doses respectivas de 5, 10 e $15 \mathrm{~mL} \mathrm{~kg}^{-1}$ de sementes. O cultivar utilizado foi $\mathrm{LG}$ 6033 VTPro2, da safra 2016/2017 da empresa LG sementes, com porcentagem de germinação de $90 \%$. As sementes foram tratadas industrialmente com os inseticidas tiametoxn e fipronil, e com o fungicida metalaxil.

A aplicação dos tratamentos foi realizada em uma amostra de 100 gramas de sementes, sendo essas sementes colocadas em embalagens plásticas transparentes, onde foi aplicada, com o auxílio de uma seringa graduada, a solução (água + produto) com os devidos tratamentos. Após a aplicação da solução, os sacos foram inflados com ar e agitados por um minuto, 
objetivando a homogeneização. Em seguida, as sementes foram dispostas sobre duas folhas de papel germitest e cobertas por outra folha, previamente umedecidas com água destilada na proporção de 2,5 vezes o peso seco. Após serem enroladas, elas foram identificadas por cada tratamento utilizado e colocadas aleatoriamente em sacolas transparentes com quatro rolos por saco. Em seguida, foram levadas para câmara de germinação B.O.D. (Demanda Bioquímica de Oxigênio) com temperatura controlada de $25^{\circ} \mathrm{C}$. Após quatro dias, foram trocadas de lugar para não haver influência da luz e deixadas por mais três dias até completar o período de avaliação, que foi de sete dias (Brasil, 2009).

Após o período sete dias, foi avaliada a porcentagem de germinação, sendo posteriormente retiradas, de forma aleatória, dez plântulas normais de cada parcela, para avaliar o crescimento aéreo, radicular e total.

Para fazer a avaliação das plântulas, foram separadas em parte aérea e sistema radicular, sendo retiradas as medidas, pesadas para obtenção da massa fresca e posteriormente colocadas em sacos de papel devidamente identificados e levados para secar em estufa com circulação forçada de ar, regulada à temperatura média de $65^{\circ} \mathrm{C}$, por um período de $48 \mathrm{~h}$. Em seguida, foi realizada a pesagem do material em balança analítica com precisão de 0,001g, obtendo-se, então, a biomassa seca. O peso de cada amostra foi dividido pelo número de plântulas (Nakagawa, 1999). Os resultados de massa seca e fresca foram expressos em mg plântula ${ }^{-1}$.

Os dados obtidos foram submetidos à análise de variância e, as médias, comparadas pelo teste de Scott Knott a 5\% de probabilidade, com auxílio do software estatístico Sisvar $^{\circledR}$ (Ferreira, 2011).

\section{Resultados e Discussão}

Os resultados analisados demonstraram que a germinação (G) não apresentou diferença significativa entre os tratamentos com os bioestimulantes (ProGibb $400^{\circledR}$ e Stimulate ${ }^{\circledR}$ ) nas doses utilizadas em relação à testemunha (Tabela 1), resultado este que confirma pesquisa recente realizada por Santos et al. (2018), que avaliaram a germinação e o desenvolvimento inicial da cultura do milho em sementes tratadas com bioestimulantes (Stimulate ${ }^{\circledR}$ e Haf Plus ${ }^{\circledR}$ ). No entanto, Castro e Vieira (2001) constataram que a aplicação do Stimulate $^{\circledR}$ na semente de milho foi significativa no processo germinativo, ocasionando um número maior de plântulas normais e a redução de desequilíbrios das mesmas.

Estudo realizado por Taiz e Zeiger (2013) mostra que o uso das giberelinas presentes no ProGibb $400^{\circledR}$ e no Stimulate ${ }^{\circledR}$ melhora o processo de germinação, devido ao fato de as giberelinas estarem relacionadas com a síntese de enzimas hidrolíticas, que degradam as proteínas e o amido, sendo usadas no desenvolvimento do embrião e também no alongamento da radícula. As giberelinas também atuam no alongamento celular, fazendo com que a raiz primária rompa os tecidos do endosperma, tegumento da semente ou estruturas do fruto que restringem o seu crescimento, fato este que poderia ter influenciado no resultado do presente trabalho, apresentando diferença dos tratamentos que foram utilizados ProGibb $400^{\circledR}$ e Stimulate ${ }^{\circledR}$ em relação aos demais; no entanto, isso não foi observado devido ao fato de o experimento ter sido conduzido em ambiente controlado. Isto foi também constatado por Bontempo et al. (2016), que, ao avaliarem a aplicação de bioestimulantes na emergência e crescimento inicial do milho em experimento a campo, não verificaram diferença significativa entre os diferentes tratamentos para a germinação das sementes, e afirmam que isso pode ser explicado pelo fato de que o experimento foi conduzido na época ideal para o cultivo, sob condições climáticas adequadas, fazendo com que os potenciais efeitos dos tratamentos não pudessem ser percebidos. A resposta à aplicação de bioestimulante é mais perceptível nas sementes quando são submetidas a condições de estresse, seja ele de caráter biótico ou abiótico, resposta esta constatada por Moterle et al. (2008) em sementes de soja.

Segundo Arteca (1996), as substâncias reguladoras podem trabalhar sozinhas, como o ProGibb $400^{\circledR}$, ou em combinação com outras, como se verifica no caso do Stimulate ${ }^{\circledR}$, que trabalha com três substâncias como auxina, citocinina e giberelina, atuando durante o processo de germinação e também no pós-emergência, realizando a mobilização de reservas e promovendo um melhor desenvolvimento inicial da plântula.

Em relação ao uso do Bacillus subtilis, não foi constatado nenhum efeito das doses utilizadas na germinação das sementes, resultado que corrobora o encontrado por Junges et al. (2013), que avaliaram a aplicação de Bacillus subtilis na semente do milho e observaram que os tratamentos não afetaram a germinação. Na cultura da aveia, Silva et al. (2002) constataram que a aplicação de Bacillus subtilis aumentou a germinação das sementes.

Os resultados demonstram que o uso do ProGibb $400^{\circledR}$ apresentou melhores valores no comprimento da parte aérea das plântulas (CPA). Os demais tratamentos não apresentaram diferença significativa entre eles. $\mathrm{O}$ maior valor apresentado com o ProGibb $400^{\circledR}$ está relacionado com a presença do ácido giberélico, que, como descrito anteriormente, tem a função de acelerar a emergência das plântulas. O mesmo não foi observado no Stimulate ${ }^{\circledR}$, que também possui o ácido giberélico, o que pode estar relacionado com a menor concentração 
do ácido giberélico em relação ao ProGibb $400^{\circledR}$. Esse crescimento inicial maior da cultura no campo apresenta certos benefícios quanto ao ataque de pragas, doenças e competição com plantas daninhas. Santos et al. (2018) constataram que a aplicação de bioestimulantes e doses dos produtos, isoladamente ou na interação entre eles, não influenciou no comprimento da parte aérea. Zanuzo et al. (2012), avaliando a influência do uso do ácido giberélico no desenvolvimento e rendimento do milho safrinha em experimento a campo, observaram que a aplicação do $\operatorname{ProGibb}^{\circledR}$ não apresentou diferença significativa para altura de planta, fitomassa total, índice de área aérea e rendimento de grãos.

$\mathrm{O}$ comprimento radicular (CR) não apresentou efeitos significativos com os tratamentos utilizados, resultado este que corrobora o trabalho de Martins et al. (2016), que avaliaram a aplicação do bioestimulante Fertiactyl $^{\circledR}$ no desenvolvimento inicial de plantas de milho tratadas via sementes e cultivadas em solos de diferentes texturas. Castro e Vieira (2001) observaram que os hormônios vegetais auxinas, citocininas e giberelinas promovem aumento no comprimento total das plantas tratadas em relação às não tratadas; os mesmos atribuem esse maior crescimento ao estímulo da divisão, à diferenciação e ao alongamento celular, resultado este não observado no presente trabalho nos tratamentos com Stimulate ${ }^{\circledR}$, que apresenta esses três hormônios. Em relação ao comprimento total das plântulas (CTP), não foi constatado efeito dos tratamentos utilizados. No entanto, avaliando o efeito da aplicação de bioestimulante $\left(\right.$ Stimulate $\left.^{\circledR}\right)$ no desenvolvimento inicial de plantas de milho, Dourado Neto et al. (2004) observaram efeito positivo da aplicação do produto no comprimento das plântulas.
Araújo (2008) observou que o tratamento de sementes de milho com Bacillus subtilis formulado com farinha de ostras (BSFO) apresenta grande potencial para aumentar o crescimento total e a nutrição das plantas.

A massa fresca da parte aérea (MFPA) e a massa fresca radicular (MVR) apresentaram resultados distintos, sendo que a primeira não apresentou diferença significativa (Tabela 2). Mazzuchelli et al. (2014), avaliando a inoculação do Bacillus subtilis na cultura do milho em trabalho realizado a campo, observaram que a aplicação desse microorganismo aumentou a massa fresca da parte aérea em aproximadamente $15 \%$. Isso provavelmente ocorreu devido ao maior tempo de contato do microorganismo com as raízes, aumentando a colonização, o que favoreceu o crescimento e desenvolvimento das plantas.

Em relação à massa fresca radicular (MFR), os tratamentos ProGibb $400^{\circledR} 1,2$ e 3 e Stimulate ${ }^{\circledR} 1$ e 2 apresentaram valores médios maiores que os demais tratamentos, resultado este que, segundo Taiz e Zeiger (2013), pode ter sido influenciado pela cinetina (citocinina), que atua na divisão celular, pelo ácido 4indol 3-ibutírico (auxina), pelo gravitropismo e pela giberelina, que atua no alongamento celular das plantas.

A massa seca da parte aérea (MSPA) apresentou diferença entre os tratamentos utilizados. Nota-se que os tratamentos ProGibb $400^{\circledR} 1,2$ e 3 apresentaram maiores médias que os demais tratamentos. Castro e Kluge (1999) descrevem que a aplicação de ácido giberélico (giberelina) em plantas de milho na fase vegetativa apresenta um maior acréscimo na parte aérea, sem afetar a produção de massa seca e produção de grãos.

Tabela 1. Germinação (G), comprimento de parte aérea (CPA), comprimento das raízes (CR) e comprimento total das plântulas (CTP) em resposta a doses de bioestimulantes (ProGibb $400^{\circledR}$ e Stimulate ${ }^{\circledR}$ ) e Bacillus subtilis na cultura do milho, comparados à testemunha.

\begin{tabular}{|c|c|c|c|c|}
\hline \multirow[t]{2}{*}{ Tratamentos } & \multirow{2}{*}{$\begin{array}{c}\mathbf{G} \\
(\%)\end{array}$} & CPA & CR & CTP \\
\hline & & \multicolumn{3}{|c|}{--------------------------------(cm)--------------------- } \\
\hline Testemunha & $89 \mathrm{a}$ & $9,07 \mathrm{~b}$ & $18,11 \mathrm{a}$ & $27,19 \mathrm{a}$ \\
\hline ProGibb $400^{\circledR} 1$ & $94 \mathrm{a}$ & $11,66 \mathrm{a}$ & $19,93 \mathrm{a}$ & $31,60 \mathrm{a}$ \\
\hline ProGibb $400^{\circledR} 2$ & $97 \mathrm{a}$ & $10,96 \mathrm{a}$ & $20,26 \mathrm{a}$ & $31,23 \mathrm{a}$ \\
\hline ProGibb $400^{\circledR} 3$ & $92 \mathrm{a}$ & $11,45 \mathrm{a}$ & $20,10 \mathrm{a}$ & $31,55 \mathrm{a}$ \\
\hline Stimulate ${ }^{\circledR} 1$ & $94 \mathrm{a}$ & $8,87 \mathrm{~b}$ & $20,28 \mathrm{a}$ & $29,16 \mathrm{a}$ \\
\hline Stimulate ${ }^{\circledR} 2$ & $94 \mathrm{a}$ & $8,28 \mathrm{~b}$ & $20,76 \mathrm{a}$ & $29,05 \mathrm{a}$ \\
\hline Stimulate ${ }^{\circledR} 3$ & $96 \mathrm{a}$ & $8,53 \mathrm{~b}$ & $19,80 \mathrm{a}$ & $28,34 \mathrm{a}$ \\
\hline Bacillus subtilis 1 & $92 \mathrm{a}$ & $9,43 \mathrm{~b}$ & $21,06 \mathrm{a}$ & $30,50 \mathrm{a}$ \\
\hline Bacillus subtilis 2 & $93 \mathrm{a}$ & $8,13 \mathrm{~b}$ & $20,02 \mathrm{a}$ & $28,16 \mathrm{a}$ \\
\hline Bacillus subtilis 3 & $94 \mathrm{a}$ & $8,80 \mathrm{~b}$ & $18,74 \mathrm{a}$ & $27,55 \mathrm{a}$ \\
\hline CV \% & 4,57 & 18,90 & 8.80 & 8,42 \\
\hline
\end{tabular}

Médias seguidas pelas mesmas letras, nas colunas, não diferem entre si pelo teste de Scott-Knott (p > 0,05). Testemunha (sementes não tratadas), ProGibb $400^{\circledR}$ (Giberelina 40\%) 1, 2 e 3 doses respectivas de 25,50 e $75 \mathrm{mg} \mathrm{kg}^{-1}$ de sementes, Stimulate ${ }^{\circledR}(0,009 \%$ de cinetina, $0,005 \%$ de auxina e $0,005 \%$ de ácido giberélico) 1,2 e 3 doses respectivas de 5,10 e $15 \mathrm{~mL} \mathrm{~kg}^{-1}$ de sementes e Bacillus subtilis 1,2 e 3 doses respectivas de 4,6 e $8 \mathrm{~mL} \mathrm{~kg}^{-1}$ de sementes. 
Tabela 2. Massa fresca da parte aérea (MFPA), massa fresca das raízes (MFR), massa seca da parte aérea (MSPA) e massa seca das raízes (MSR) em resposta a doses de bioestimulantes (ProGibb $400^{\circledR}$ e Stimulate ${ }^{\circledR}$ ) e Bacillus subtilis na cultura do milho, comparados à testemunha.

\begin{tabular}{|c|c|c|c|c|}
\hline \multirow[t]{2}{*}{ Tratamentos } & MFPA & MFR & MSPA & MSR \\
\hline & \multicolumn{4}{|c|}{ 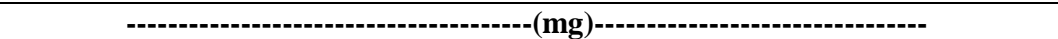 } \\
\hline Testemunha & $520,00 \mathrm{a}$ & $595,00 \mathrm{~b}$ & $96,80 \mathrm{~b}$ & $110,00 \mathrm{a}$ \\
\hline ProGibb $400^{\circledR} 1$ & $520,00 \mathrm{a}$ & $642,50 \mathrm{a}$ & $111,20 \mathrm{a}$ & $122,50 \mathrm{a}$ \\
\hline ProGibb $400^{\circledR} 2$ & $575,00 \mathrm{a}$ & $667,50 \mathrm{a}$ & $112,38 \mathrm{a}$ & $135,00 \mathrm{a}$ \\
\hline ProGibb $400^{\circledR} 3$ & $560,00 \mathrm{a}$ & $630,00 \mathrm{a}$ & $114,00 \mathrm{a}$ & $122,50 \mathrm{a}$ \\
\hline Stimulate 1 & $482,50 \mathrm{a}$ & $665,00 \mathrm{a}$ & $102,62 \mathrm{~b}$ & $130,00 \mathrm{a}$ \\
\hline Stimulate 2 & $447,50 \mathrm{a}$ & $622,50 \mathrm{a}$ & $100,78 \mathrm{~b}$ & $127,50 \mathrm{a}$ \\
\hline Stimulate 3 & $427,50 \mathrm{a}$ & $567,50 \mathrm{~b}$ & $100,27 \mathrm{~b}$ & $125,00 \mathrm{a}$ \\
\hline Bacillus Subtilis 1 & $462,50 \mathrm{a}$ & $572,50 \mathrm{~b}$ & $97,13 \mathrm{~b}$ & $122,50 \mathrm{a}$ \\
\hline Bacillus Subtilis 2 & $417,50 \mathrm{a}$ & $582,50 \mathrm{~b}$ & $95,98 \mathrm{~b}$ & $122,50 \mathrm{a}$ \\
\hline Bacillus Subtilis 3 & $520,00 \mathrm{a}$ & $550,00 \mathrm{~b}$ & $98,75 \mathrm{~b}$ & $115,00 \mathrm{a}$ \\
\hline CV \% & 18.02 & 9.14 & 7,98 & 9,31 \\
\hline
\end{tabular}

Médias seguidas pelas mesmas letras, nas colunas, não diferem entre si pelo teste de Scott-Knott (p > 0,05). Testemunha (sementes não tratadas), ProGibb $400^{\circledR}$ (Giberelina 40\%) 1, 2 e 3 doses respectivas de 25,50 e $75 \mathrm{mg} \mathrm{kg}^{-1}$ de sementes, Stimulate ${ }^{\circledR}(0,009 \%$ de cinetina, 0,005\% de auxina e 0,005\% de ácido giberélico) 1,2 e 3 doses respectivas de 5,10 e $15 \mathrm{~mL} \mathrm{~kg}^{-1}$ de sementes e Bacillus subtilis 1,2 e 3 doses respectivas de 4,6 e $8 \mathrm{~mL} \mathrm{~kg}^{-1}$ de sementes.

Em relação à massa seca radicular (MSR), observase que não houve diferença entre os tratamentos. No entanto, Ferreira et al. (2007) observaram que o uso de bioestimulantes em sementes de milho apresentou diferenças expressivas no aumento da massa seca das raízes. Segundo Taiz e Zeiger (2013), o uso de giberelinas presentes nos bioestimulantes utilizados no presente estudo, quando utilizadas no tratamento de sementes, resulta em maior crescimento do caule das plantas; já para o crescimento da raiz, o efeito não é significativo, porém, quando o produto é aplicado na parte aérea da planta, ocorre crescimento expressivo do caule e da raiz. Santos et al. (2013), avaliando o uso de bioestimulantes no crescimento de plantas de milho, constataram efeitos positivos na maioria das características fisiológicas das plantas, sendo o melhor incremento da massa seca das raízes.

Nos tratamentos com o uso do Bacillus subtilis não foram verificados efeitos no aumento da massa seca da raiz, o que era esperado, já que a aplicação do Bacillus subtilis na planta provoca a indução de fito-hormônios, como ácido indolacético, ácido abscísico, giberelinas e citocininas, o que favorece o crescimento radicular e o aumento do número de pelos radiculares, aumentando a massa radicular (Araújo e Hungria, 1999). Possivelmente, esse efeito não ocorreu no presente trabalho devido ao curto período de condução do experimento, pois os microrganismos necessitam de maior período de tempo para a formação de colônias nas raízes, que reflitam em resposta positiva às plantas.

\section{Conclusões}

A aplicação de ProGibb $400^{\circledR}$, Stimulate ${ }^{\circledR}$ e Bacillus subtilis não influenciou na germinação, comprimento das raízes e comprimento da parte aérea, massa fresca da parte aérea e massa seca das raízes na cultura no milho.

A aplicação do ProGibb $400^{\circledR}$ nas doses 25,50 e 75 $\mathrm{mg} \mathrm{kg}{ }^{-1}$ de sementes aumentou o comprimento e a massa seca da parte aérea no início do desenvolvimento da cultura do milho.

\section{Referências Bibliográficas}

Alves, B.M, Cargnelutti Filho, A., Toebe, C.B.M., Silva, L.P., 2015. Divergência genética de milho transgênico em relação à produtividade de grãos e da qualidade nutricional. Ciência Rural, 45(5), 884-891.

Araújo, F.F., 2008. Inoculação de sementes com Bacillus subtilis, formulado com farinha de ostra e desenvolvimento de milho, soja e algodão. Ciência e Agrotecnologia, 32(2), 456462.

Araújo, F.F., Hungria, M., 1999. Nodulação e rendimento de soja co-infectada com Bacillus subtilis e Bradyrhizobium japonicum/Bradyrhizobium elkanii. Pesquisa Agropecuária Brasileira, 34(9), 1633-1643.

Arteca, R.N., 1996. Plant growth substances: principles and applicacions. New York, Chapman \& Hall.

Bertolin, D.C., Sá, M.E., Arf, O., Haga, K.Y., Abrantes, L.F., Nogueira, D.C., 2008. Efeito de bioestimulantes no teor e no rendimento de proteínas de grãos de soja. Agrarian, (2), 23-34.

Bontempo, A.F., Alves, F.M., Carneiro, G.D.O.P., Machado, L.G., Silva, L.O.D., Aquino, L.A., 2016. Influência de bioestimulantes e nutrientes na emergência e no crescimento inicial de feijão, soja e milho. Revista Brasileira de Milho e Sorgo, 15(1), 86-93.

Brasil. Ministério da Agricultura e Reforma Agrária, 2009. Regra para análise de sementes. Brasília, SNDA/DND/CLAV, $308 \mathrm{p}$. 
Castro, P.R.C., Kluge, R.A., 1996. Ecofisiologia de cultivos anuais. São Paulo, Nobel.

Castro, P.R.C., Vieira, E.L., 2001. Aplicações de reguladores vegetais na agricultura tropical. Guaíba: Agropecuária.

Dourado Neto, D., Dario, G.J.A., Barbieri, A.P.P., Martin, T.N., 2014. Ação de bioestimulantes no desempenho agronômico de milho e feijão. Bioscience Journal, 30(3), 371379.

Dourado Neto, D., Dario, G.J.A., Vieira Júnior, P.A., Manfron, P.A., Martin, T.N., Bonnecarrére, R.A.G., Crespo, P.E.N., 2004. Aplicação e influência do fitorregulador no crescimento das plantas de milho. Revista da Faculdade de Zootecnia, Veterinária e Agronomia, 11(1), 1-9.

Ferreira, D.F., 2011. Sisvar: A computer statistical analysis system. Ciência e Agrotecnologia, 35(6), 1039-1042.

Ferreira, L.A., Oliveira, J.A., Von Pinho, É.V.R., Queiroz, D.L., 2007. Bioestimulante e fertilizante associados ao tratamento de sementes de milho. Revista Brasileira de Sementes, 29(2), 80-89.

Junges, E., Toebe, M., Santos, R.F.D., Finger, G., Muniz, M.F.B., 2013. Effect of priming and seed-coating when associated with Bacillus subtilis in maize seeds. Revista Ciência Agronômica, 44(3), 520-526.

Klahold, C.A., Guimarães, V.F., Echer, M.M., Klahold, A., Contiero, R.L., Becker, A., 2006. Resposta da soja (Glycine $\max ($ L.) Merrill) à ação de bioestimulante. Acta Scientiarum Agronomy, 28(2), 179-185.

Martins, A.G., Rampim, L., Rosset, J.S., Prior, M., Coppo, J.C., 2016. Aplicação de bioestimulante em sementes de milho cultivado em solos de diferentes texturas. Scientia Agraria Paranaensis, 15(4), 440-445.

Mazzuchelli, R.D.C.L., Sossai, B.F., Araújo, F.D., 2014. Inoculação de Bacillus subtilis e Azospirillum brasilense na cultura do milho. Colloquium Agrarie, 10(2), 40-47.
Moterle, L.M., Santos, R.F., Braccini, A.L., Scapim, C.A., Barbosa, M.C., 2008. Efeito da aplicação de biorregulador no desempenho agronômico e produtividade da soja. Acta Scientiarum. Agronomy, 30(5), 701-709.

Nakagawa, J., 1999. Teste de vigor baseado no desempenho das plântulas, in: Krzyzamowski, F.C., Vieira, R.D., França Neto, J.B., (Ed.), Vigor de sementes: conceito e testes. Londrina, ABRATES, p. 1-24.

Santos, D.G., Yamashita, O.M., Carvalho, M.A.C., Oliveira, L.C.A., Rabelo, H.O., Mera, L.P., Rocha, A.M., 2018. Germination and Early Development of Corn Seeds under the Influence of Plant Growth Regulator. Journal of Agriculture and Ecology Research International, 17(1), 1-6.

Santos, V.M., Melo, A.V., Cardoso, D.P., Gonçalves, A.H., Varanda, M.A.F., Taubinger, M., 2013. Uso de bioestimulantes no crescimento de plantas de Zea mays L. Revista Brasileira de Milho e Sorgo, 12(3), 307-318.

Silva, R.T.V, Homechini, M., Endo, R.M., Fonseca, I.C.B, 2002. Efeito do tratamento de semente e da profundidade de semeadura no desenvolvimento de plantas de aveia-branca (Avena sativa L.) e a microflora da rizosfera e do rizoplano. Revista Brasileira de Sementes, 24(1), 237-243.

Silva, T.T.A., Von Pinho, E.V.R, Cardoso, D.L., Ferreira, C.A., Alvim, P.O., Costa, A.A.F., 2008. Qualidade fisiológica de sementes de milho na presença de bioestimulantes. Ciência Agrotecnologia, 32(3), 840-846.

Taiz, L., Zeiger, E., 2013. Fisiologia vegetal, quinta ed. Porto Alegre, Artmed.

Zanuzo, M.R., Lermenn, F., Bezerra, E.L., 2012. Influência do uso de ácido giberélico (AG), no desenvolvimento e rendimento de milho safrinha. Uniciências, 16(1), 25-31. 